\title{
Fluticasone propionate in inflammatory bowel disease
}

\author{
MARTA CARPANI DE KASKI, MD, HUMPHREY JF HODGSON, DM, FRCP
}

\begin{abstract}
Although effective for both acute and often long term treatment of inflammatory bowel disease, systemically absorbed corticosteroids have a high incidence of side effects. This article briefly reviews the pharmacokinetics of corticosteroids and the strategies available for reducing systemic side effects. In particular, fluticasone propionate is a fluorinated glucocorticoid, in which systemic side effects are absent or minimal due to its relatively low absorption and rapid first pass metabolism. In an open trial in 12 patients with mild and moderately active Crohn's disease, administration of $20 \mathrm{mg}$ fluticasone propionate orally was associated with a significant fall in the Crohn's disease activity index and improvement in other parameters of inflammation, without change in either plasma cortisol levels or responsiveness to adrenocorticotropic hormone, suggesting that this drug is a promising therapy for Crohn's disease meriting evaluation against conventional corticosteroids. Can J Gastroenterol $1990 ; 4(7): 417-419$
\end{abstract}

Key Words: Clinical trial, Corticosteroids, Crohn's disease, Fluticasone propionate

\section{Le propionate de fluticasone dans les maladies inflammatoires de l'intestin}

RESUME: Bien qu'efficaces dans le traitement des maladies inflammatoires de l'intestin - aiguës et à long terme, les corticostéroïdes absorbés par voie générale s'accompagnent d'une incidence élevée d'effets indésirables. Le présent article examine rapidement la pharmacocinétique des corticostéroïdes ainsi que les stratégies permettant de réduire les effets secondaires systémiques. Il note que le propionate de fluticasone est un glucocorticoïde fluoré dont les effets secondaires sont absents ou minimes en raison de son absorption faible et de son métabolisme rapide de premier passage. Dans un essai ouvert, 12 patients porteurs d'une maladie de Crohn faiblement ou modérément active ont reçu du propionate de fluticasone oral à la dose de $20 \mathrm{mg}$. Les résultats - chute significative du CDAI et amélioration des paramètres inflammatoires, sans changement des taux plasmatiques de cortisol ou de la réponse à l'ACTH - suggèrent que ce médicament pourrait offrir un remède prometteur à la maladie de Crohn et qu'il mérite d'être évalué par rapport aux corticostéroïdes conventionnels.

\section{Royal Postgraduate Medical School, Hammersmith Hospital, London, United Kingdom}

Correspondence and reprints: Dr M Carpani de Kaski, Royal Postgraduate Medical School, Hammersmith Hospital, London, United Kingdom W12 OH5. Telephone (081) 743-2030
C ORTICOSTEROIDS ARE THE MOST effective single class of drugs available for the treatment of inflammatory bowel disease (IBD). In controlled therapeutic trials they have been demonstrated to be effective in the treatment of acute ulcerative colitis and active Crohn's disease (1). They are more effective than salazopyrine and similar drugs in the treatment of active colonic Crohn's disease $(1,2)$, and it is only in mild cases of ulcerative colitis that it appears that 5-aminosalicylate therapy may be as effective.

In addition to their undoubted efficacy in treating active disease, corticosteroids play a substantial role in maintaining remission or suppressing disease activity long term. While in ulcerative colitis this is resorted to only rarely, a substantial proportion of patients with Crohn's disease who enter remission on steroid therapy become steroid-dependent (2). There is controlled evidence of the value of low dose steroid therapy ( $8 \mathrm{mg}$ methylprednisolone per day) in maintaining remission in such patients (2).

This beneficial effect is however undoubtedly achieved at the price of considerable side effects. In the multicentre National Cooperative Crohn's Disease study (3), prednisolone given orally ( 0.05 to $0.75 \mathrm{mg} / \mathrm{kg}$ body weight) for 17 weeks caused obvious side effects (moon face, acne, ecchymosis, hyper- 
tension) in over $50 \%$ of patients when used to treat active disease. Side effects were seen in approximately one-third of patients when lower doses were used in an attempt to maintain remission ( $0.25 \mathrm{mg} / \mathrm{kg}$ body weight). Long term administration of prednisolone also resulted in a significant rise in blood leukocytes and hematocrit values.

A more recent study evaluated the incidence of osteoporosis in patients with IBD and reported that $30 \%$ of the patients studied were osteoporotic (4). Those at highest risk were patients with longstanding, severe small intestinal disease; those with intestinal resection, secondary amenorrhea or premature menopause; and those on high dose steroid therapy. There was a clear negative correlation between lifetime steroid dose and bone mineral content. Another study reported that $4.3 \%$ of patients treated with corticosteroids for IBD over a 10 year period developed osteonecrosis (5). Side effects are seen both with enemas and with oral or intravenous therapy. In mild disease, enemas have been shown to be more efficient than systemic steroids if the effect is related to the plasma cortisol achieved (6). This in itself is not surprising. Unfortunately, it is not possible to limit corticosteroid therapy to local use, as local enema administration rarely stretches more proximally than the descending colon. Studies confirm the absorption of enemas that may be up to $50 \%$ of the injected dose (6).

The diversity and severity of side effects has stimulated the development of different approaches to steroid therapy. The use of an alternate day regimen of $40 \mathrm{mg}$ prednisolone orally was shown to maintain remission in patients with frequently relapsing ulcerative colitis (7). Even then, side effects attributable to prednisolone, although mild, were seen after three months of treatment. The use of alternate day therapy has been suggested in Crohn's disease, but this has not been tested in controlled trials.

In Crohn's disease azathioprine at a dosage of $2 \mathrm{mg} / \mathrm{kg}$ has been used as an adjunct permitting a reduction in steroid dosage in patients in steroiddependent remission $(8,9)$. Many physicians, however, hesitate to do this because of the significant, though low, complication rate from azathioprine use. The care of patients with IBD would be substantially enhanced by modifications of existing corticosteroids to permit the current therapeutic effects with fewer side effects.

Corticosteroids are in general rapidly and fairly effectively absorbed from the gastrointestinal tract. Of oral doses, approximately $80 \%$ of prednisolone, $70 \%$ of methylprednisolone, and $50 \%$ of hydrocortisone become systemically bioavailable. The absorbability can be enhanced by substituting lipophilic groups on the 'D' portion of the steroid ring structure (10). Disease affecting the small intestine, notably Crohn's disease, has been shown to be associated with a lower absorption of prednisolone (11). During active colitis the rate of absorption may be slowed but the final amount absorbed is not reduced.

Once absorbed, corticosteroids are $90 \%$ protein-bound, either to albumin or to a specific corticosteroid-binding glycoprotein. The latter is of higher affinity but relatively low capacity, and does not bind some of the newer corticosteroids (12). Clearly, coexistent hypoalbuminemia due to a proteinlosing enteropathy is likely to reduce the binding capacity of the serum.

Fluorination in the B-ring (at the ' 9 ' position) tends to increase corticosteroid activity of both gluco- and mineralocorticoid-type, in association with a slowing of metabolism. A double bond in the A-ring between the ' 1 ' and ' 2 ' positions increases the affinity for the glucocorticoid - but not the mineralocorticoid - receptor. An oxygen function at the ' 11 ' position in the $\mathrm{C}$-ring is required for glucocorticoid receptor binding (10).

Metabolism of synthetic corticosteroids may be by a number of different routes, including oxidative biotransformation by the liver or thiol ester hydrolysis, depending on the substitutions existing on the steroid ring (12).

The ideal new drug for treating IBD would be a nonsystemically available corticosteroid, with marked local potency - a true 'nonabsorbable steroid'. Although this phrase is widely used, it is a shorthand for classes of steroids which have a varying combination of low absorption from the gastrointestinal tract and rapid metabo. lism. Various chemical modifications of the steroid molecule may enhance metabolism by different pathways. So far, four 'nonabsorbable steroids' have been used in clinical trials, mainly in enema form in IBD: budesonide (13), beclomethasone (14), tixocortol (15-17) and fluticasone. Fluticasone propionate is a fluorinated glucocorticoid steroid. It has relatively low absorption but rapid first pass metabolism, and in volunteer studies over two weeks it has not been associated with depression of the hypothalamic-pituitary-adrenal axis. Only early data on its clinical use are available. It has been used in the treatment of celiac disease, where improvement of biopsy appearances is known to occur with oral prednisolone. Twelve untreated patients received six weeks of fluticasone treatment while maintaining a normal diet. After treatment there was symptomatic improvement in 10 patients, with a mean weight gain of $2 \mathrm{~kg}$, a rise in hemoglobin and a mean albumin of 5.4 $\mathrm{g} / \mathrm{L}$. Permeability tests and biopsies also showed the benefits of the drug without appreciable side effects (18). Whether this is better long term treatment for celiac disease than gluten withdrawal seems unlikely, but the study is of interest as it suggests an effective local antiinflammatory - and maybe immunosuppressive - action of the drug in the gut.

The authors have used this drug in an open trial, admitting 12 patients with systemic relapses of Crohn's disease to a three week assessment of the effect of $20 \mathrm{mg}$ of fluticasone propionate, assessing disease activity from the clinical parameters of the Crohn's disease activity index (CDAI), and using the technique of indium leukocyte scanning and whole body counting to assess activity (19).

The results were encouraging, witha significant fall in CDAI during the course of the treatment $(193 \pm 84$ versus $121 \pm 50[\mathrm{P}<0.01])$. The appearances of the indium leukocyte scans were im. proved in eight of the 12 patients, to 
the extent that seven no longer had abnormal distribution of activity, and one had less activity. Whole body excretion data showed a reduction in labelled granulocyte excretion from $28 \pm 21 \%$ to $14 \pm 7 \% \quad(\mathrm{P}<0.05)$. This treatment was well tolerated and there was no change in either plasma cortisol levels or responsiveness to adrenocorticotropic hormone. Conclusions from this study were that fluticasone propionate was a promising therapy for Crohn's disease which needed assessment versus conventional corticosteroids (20).

\section{REFERENCES}

1. Summers RW, Switz DM, Sessions JT, et al. National cooperative Crohn's disease study: Results of drug treatment. Gastroenterology 1979;77:847-69.

2. Best WR, Becktel JM, Singleton JW. Rederived values of the eight coefficients of the Crohn's disease activity index (CDAI). Gastroenterology 1979; 77:843-6.

3. Singleton JW, Law DH, Kelley ML, et al. National Cooperative Crohn's disease study: Adverse reactions to study drugs. Gastroenterology 1979;77:870-82.

4. Compston JE, Judd D, Crawley EO, et al. Osteoporosis in patients with inflammatory bowel disease. Gut 1987;28:410-5.

5. Vakil N, Sparberg M. Steroid-related osteonecrosis in inflammatory bowel disease. Gastroenterology 1989;96:62-7.

6. Farmer RG, Schumachier OP. Treatment of ulcerative colitis with hydrocortisone enemas: Relationship of hydrocortisone absorption, adrenal suppression and clinical response. Dis Colon Rectum 1970;13:355.

7. Powell-Tuck J, Bown RL, Chambers TJ, et al. A controlled trial of alternate day prednisolone as a maintenance
For a small group of patients with frequently relapsing ulcerative colitis, and for a substantially larger group of patients with readily relapsing Crohn's disease, the availability of locally active corticosteroids which could control disease activity without systemic effects would be a major advance. If this effect can be proven, it would also have biological significance, indicating that the inflammatory process of IBD can be controlled within the mucosa - ie, the superior effectiveness of systemic corticosteroids as currently used is not some central action, for example at

treatment for ulcerative colitis in remission. Digestion 1981;22:263-70.

8. O'Donoghue DP, Dawson AM, PowellTuck J, et al. Double-blind withdrawal trial of azathioprine as maintenance treatment for Crohn's disease. Lancet 1978;ii:955-7.

9. Willoughby JMT, Kumar PJ, Beckett J, et al. Controlled trial of azathioprine in Crohn's disease. Lancet 1971;ii: 944-7.

10. Swartz SL, Dluhy RG. Corticosteroids: Clinical pharmacology and therapeutic use. Drugs 1978;16:238-55.

11. Shaffer JA, Williams SE, Turnberg LA, et al. Absorption of prednisolone in patients with Crohn's disease. Gut 1983;24:182-6.

12. Al-Habet S, Rogers HJ. Pharmacokinetics of intravenous and oral prednisolone. $\mathrm{Br} \mathrm{J}$ Clin Pharmacol 1980;10:503-8.

13. Danielson A, Hellers G, Lyrenas E, et al. A controlled randomised trial of budesonide versus prednisolone retention enemas in active distal ulcerative colitis. Scand J Gastroenterol 1987;22:987-92.

14. Kumana CR, Meghji M, Seaton T, et al. Beclomethasone dipropionate enemas for treating inflammatory bowel disease without producing thymus, bone marrow or mesenteric lymph nodes, but merely that a higher dose is delivered to the gastrointestinal tissues.

For long term use, nonabsorbable corticosteroids will require close assessment, with particular attention to whether or not side effects such as tissue atrophy occur. Studies have indicated that the lung, receiving inhaled steroids, is substantially less sensitive in terms of inhibition of ground substance (hyaluronic acid) synthesis than the skin, and the results of such studies in gut would be of substantial interest.

Cushing's syndrome or hypothalamic pituitary adrenal suppression. Lancet 1982; i:579-83.

15. Larochelle P, DuSouich P, Bolte E, et al. Tixocortol pivalate, a corticosteroid with no systemic glucocorticoid effect after oral, intrarectal, and intranasal application. Clin Pharmacol Ther 1983;22:343-50.

16. Levinson RA. Intrarectal treatment of ulcerative colitis with tixocortol pivalate, a topical nonsystemic anti-inflammatory steroid, comparison with hydrocortisone enema. Gastroenterology 1986;90:1520.

17. Hanauer SB. Clinical experience with tixocortol pivalate. Can J Gastroenterol 1988;2:156-8.

18. Mitchison $\mathrm{H}, \mathrm{Al}$ Mardini H, Zaitoun A, Record CO. Beneficial effects of the topical steroid fluticasone proprionate in untreated coeliac disease. Gut 1989;30:A1451.

19. Carpani M, Peters AM, Hodgson HJF, et al. Quantification of whole body granulocyte excretion inflammatory bowel disease. Nucl Med Comm 1989;10:267.

20. Carpani de Kaski M, Peters AM, Lavender JP, et al. Oral fluticasone propionate in active Crohn's disease. Gut 1989;30:A1480. 


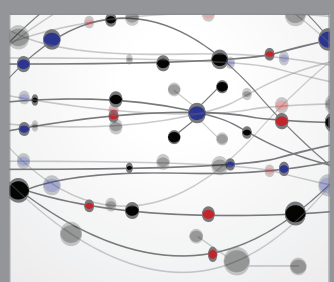

The Scientific World Journal
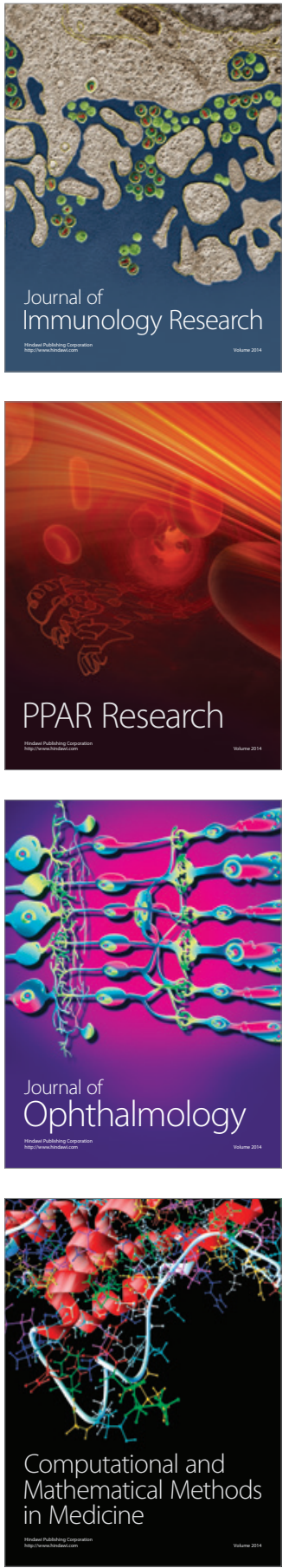

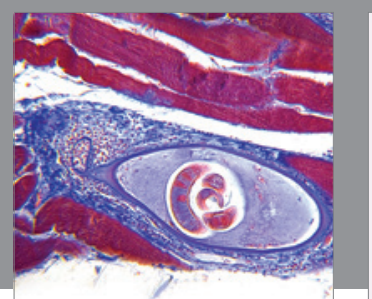

Gastroenterology Research and Practice

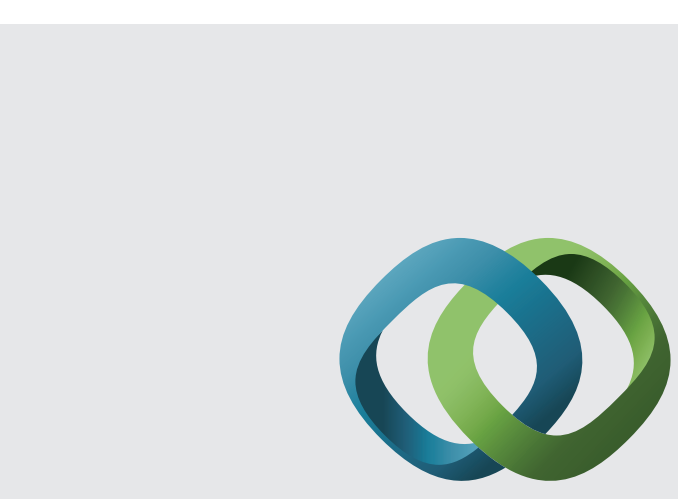

\section{Hindawi}

Submit your manuscripts at

http://www.hindawi.com
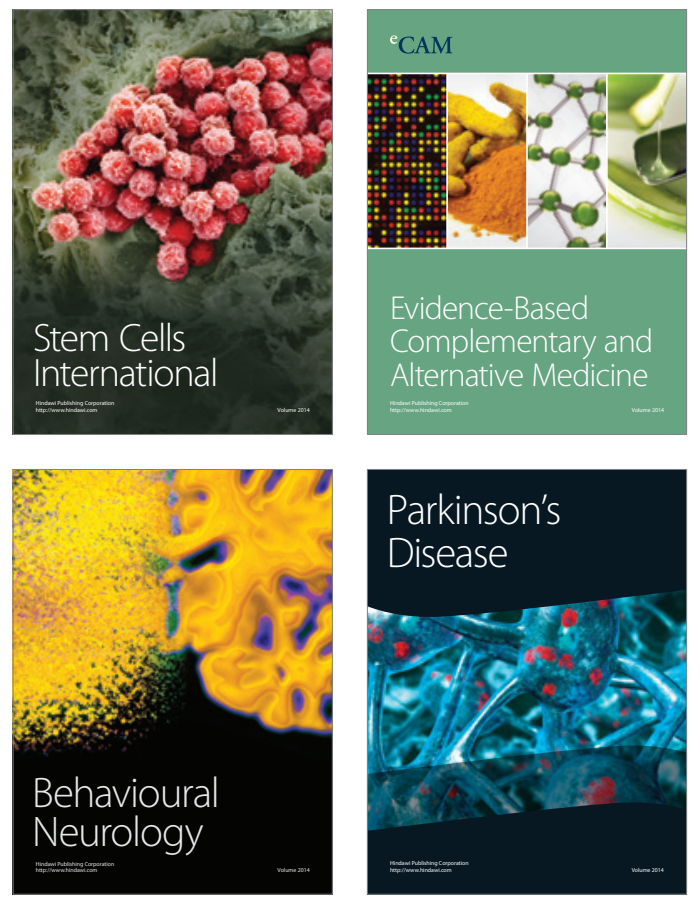
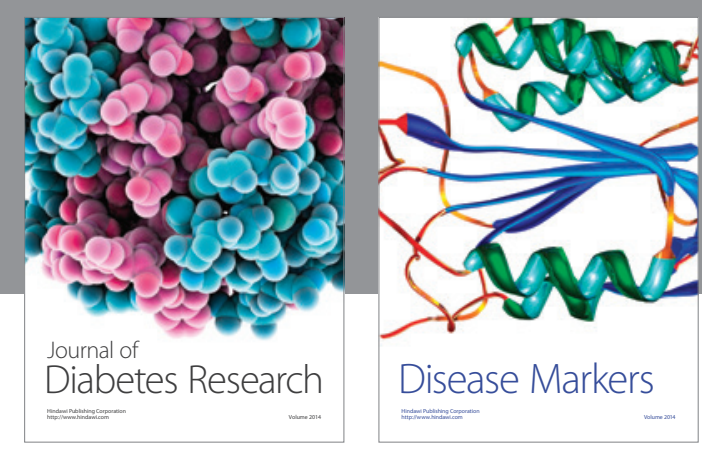

Disease Markers
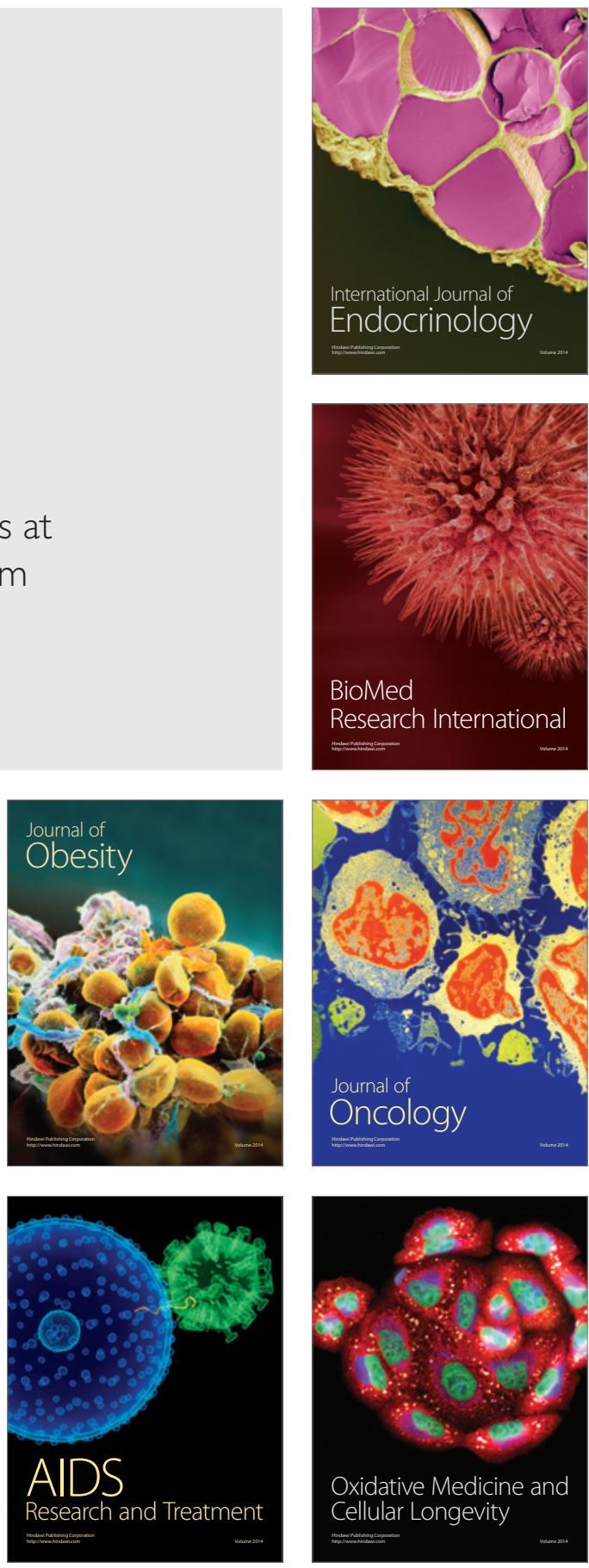